\title{
Experimental Investigations of Mechanical Characteristics and Tribological Mechanisms of Nanometric Zirconia Dental Ceramics
}

\author{
Changhe $\mathrm{Li}^{*}{ }^{, 1}$, Zhanrui Liu ${ }^{1}$, Guoyu Liu ${ }^{2}$ and Yucheng Ding ${ }^{1}$ \\ ${ }^{1}$ School of Mechanical Engineering, Qingdao Technological University, 266033, China \\ ${ }^{2}$ Inner Mongolia University for Nationalities, Tongliao, 028042, China
}

\begin{abstract}
This study was focused on the experimental investigations about mechanical characteristics and tribological mechanisms of nanometric zirconia dental ceramics. A universal mechanical testing machine was used to test the threepoint flexural strength and the fracture toughness. A microhardness tester was used to test the Vickers hardness of the test specimens. An MRH-3 digital-display high-speed ring-on-block tribometer was used for frictional wear experiments. A PGI800 coarseness profiling instrument was used to test the width and the length of the grinding defects on specimen surfaces. An S-3500N SEM was employed in the microscopic observation of the surface morphology after the abrasion. Results indicates that the flexural strength of the test specimens $\geq 890 \mathrm{MPa}$, the fracture toughness $\geq 6 \mathrm{Mpa} . \mathrm{m}^{1 / 2}$, the Vickers hardness $\geq 1240 \mathrm{MPa}$, the linear contraction $\geq 21 \%$, and the apparent porosity $\geq 0.32 \%$. Moreover, the frictional factor and the wear rate of nanometric $\mathrm{ZrO}_{2}$ ceramics decreased significantly under identical working and frictional conditions compared with $\mathrm{ZrO}_{2}$. The wear mechanism of nanometric $\mathrm{ZrO}_{2}$ ceramics was micromachining and plastic deformation while the wearing mechanism of $\mathrm{ZrO}_{2}$ ceramics was brittle fracture and abrasive wear.
\end{abstract}

Keywords: Nanometric zirconia, Dental ceramics, Mechanical characteristics, Frictional wear mechanisms.

\section{INTRODUCTION}

Since zirconia ceramics has excellent biocompatibility, it has not only been widely applied as the replacement material for the head of femur, but also as a tooth-planting material since it possesses the following advantages: Corrosion resistance, good chemical stability, innocuity and no sensibilization; Enough strength and the highest roomtemperature toughness among ceramics; Low thermal conductivity, intraoral modification and no heat transfer to hurt the bone tissue; No generation of galvanic electricity; Better X-ray resistance than bones, which facilitates postoperation observation, and no influence on patients' NMR imaging; Good appearance. It can achieve the best artistic coordination with the gingiva mucosa, and the dark grey of metal foundationpiles can be avoided. In 1997, Pigot planted $141 \mathrm{ZrO}_{2}$ ceramic endosteal implants in the lower jawbones of 39 patients to support the complete lower denture and achieved a better clinical effect compared with that of $\mathrm{Ti}$ implants in the corresponding period [1-4]; Schultze designed an animal model with apiceotomy being conducted and used $\mathrm{ZrO}_{2}$ ceramics as inside-fang and insidebone implants, with which not only excellent root canal sealing could be formed, but osseointegration could be achieved so that the teeth could be more stabilized; Percy Milleding tested the characteristics of the biomembrane formed by salivary protein and plasma protein on different kinds of dental ceramics and noticed that no salivary protein was adsorbed at the surface of zirconia ceramics but all plasma protein appeared on the biomembrane at the surface

\footnotetext{
*Address correspondence to this author at the School of Mechanical Engineering, Qingdao Technological University, 266033, China; Tel: +860532-85071757; E-mail: sy_lichanghe@163.com
}

of zirconia ceramics. Such a weak adsorption to salivary protein not only occurred in $\mathrm{ZrO}_{2}$ ceramics but in $\mathrm{Al}_{2} \mathrm{O}_{3}$ ceramics. The planting of bacteria on dental surfaces is closely related to the formation of the salivary pellicle, which explains the lower adhesive rate of the dental plaque on all-ceramic crowns in clinical practice. On the other hand, $\mathrm{ZrO}_{2}$ ceramics has great adsorption to haemocyanin (e.g., fibrinogen) while the fibrinogen and fibronectin, etc. which are adsorbed at the surface of a solid material, can promote the adhesion of cells against the material and further affect the integration of the material with the tissue. Accordingly, such great adsorption against haemocyanin is favorable to the firm bond between $\mathrm{ZrO}_{2}$ ceramics and the tissue, which suggests that $\mathrm{ZrO}_{2}$ ceramics is suitable to be used as an oral planting material $[5,6]$. Besides, it favors the bond between the soft gum tissue at the cervical margin and the implant, the reduction of dental plaque aggregation and the health of the implant and surrounding soft tissue. As a bone replacing material, zirconia ceramics can form close chemical bond with the bone tissue in the organism and has excellent biocompatibility and biological activity. Ever since it came out as a novel biological material in 1970s, it has become the most promising material for replacing hard tissue. However, its high fragility and low strength restricted its application in the weight-bearing parts in the human body, so the selective addition of second-phase particles and whiskers as well as other methods were adopted to improve its mechanical properties. $\mathrm{Xu}$ Shuhua and Huang Chuanyong also made studies on the microstructures and properties of $\mathrm{HA}-\mathrm{ZrO}_{2}$ composite materials $[7,8]$. For the past few years, artistic and non-toxic all-ceramic restoration with superior biocompatibility has become a research frontier and the development direction of the Prosthetic Dentistry. The InCeram series produced by VITA are so far the most 
successful all-ceramic series that are applied in clinical practice. With the three-point flexural strength of $513 \mathrm{MPa}$ and the fracture toughness as high as $4.0 \mathrm{MPa} \cdot \mathrm{m}^{1 / 2}$, Zirconia Toughened Alumina (ZTA) ceramics can be used to repair posterior crowns and bridges. Suarez made three years of clinical observations on the fixed bridges of the posterior teeth repaired with In-CeramZirconia and believed that the all-ceramic fixed bridges achieved good clinical effects during the observation period. However, long-term observation was required due to its short-time clinical application. Berit studied the chemical stability and lowtemperature aging performance of phase-transition ZTA toughened ceramics when it was applied to dental inlay, crowns and bridges. He believed that the phase-transition $\mathrm{ZrO}_{2}$ toughened ceramics had better mechanical properties than other dental ceramics, and its chemical stability also met the requirement when it was used as dental ceramics. Quinn et al. studied the effects of microstructures and the chemical composition on the mechanical properties of dental ceramics and also believed that $\mathrm{ZrO}_{2}$ ceramics possessed better mechanical properties as dental ceramics. Chinese scholars also energetically explored the application of zirconia ceramics in the stomatology. Chai Feng, Xu Ling and Liao Yunmao introduced nanometer materials in the studies on In-Ceram materials. With nanometric zirconia powder being added in micro-metric $\alpha-\mathrm{Al}_{2} \mathrm{O}_{3}$ powder, they fabricated zirconia-toughened nanometric composite ceramics and systematically studied the relationships of the powder particle size, the content of nanometric zirconia powder and the sintering temperature, etc. [9, 10]. with the matrix strength, so as to obtain more superior repairpurposed all-ceramic materials using advanced nanomaterial technologies. As a novel fine ceramic material, ZTC has found more and more extensive applications in medicine. Present research and development of nanometric zirconia ceramics has become very popular, and it will be the direction to study and develop better zirconia ceramics to meet the requirements of medical materials using nanometer materials technologies. This study was focused on the experimental investigations of the mechanical characteristics and frictional wear mechanisms of nanometric zirconia ceramics for dental purposes.

\section{EXPERIMENTAL SETUP}

The material adopted for the experiment was selfdeveloped yttria-stabilized nanometric zirconia ceramics, i.e., $3 \mathrm{Y}$-TZP $\left(3 \mathrm{molY}_{2} \mathrm{O}_{3}+\mathrm{ZrO}_{2}\right)$. As self-developed nanometric composite zirconia powder, the material was formed by cold isostatic pressing after the dry-pressing at $200 \mathrm{Mpa}$, and was fabricated through sintering at $1450^{\circ} \mathrm{C}$ under normal pressure. Then, specimens required were obtained after diamond cutting and the ground finish of a precision grinder. The density and the apparent porosity of the specimens was tested with the Archimedes drainage method. The length variation of the specimens before and after the sintering was measured with a vernier caliper, and the linear contraction was tested. An X-ray diffractometer was used for the specimen phase analysis. SEM was used to observe the section micrograph of the specimens. A universal mechanical testing machine was used to test the three-point flexural strength and the fracture toughness. A microhardness tester was used to test the Vickers hardness of the test specimens. An MRH-3 digital-display high-speed ring-on-block friction tester was employed for the test of friction and wear behavior. The friction tester was in a tower structure. A stepping motor controlled the loading of a lever. All experimental parameters were configured in blocks, and the friction pair was in the ring-on-block form. The test ring was mounted at the front end of the spindle. When the test ring revolved with the spindle, sliding friction occurred between the test ring and the test block. The pressure and the friction between the test ring and the test block could be read out from the instrument on the tribometer directly. The rotation speed of the tribometer spindle varied within the scope of $360-840 \mathrm{r} / \mathrm{min}$. The load (experimental force) was $100-1000 \mathrm{~N}$. The lubrication medium was artificial saliva.

The specimen for the friction wear test was cut into $19 \mathrm{~mm} \times 13 \mathrm{~mm} \times 11.7 \mathrm{~mm}$ blocks with a diamond wire saw. After the ground finish of a precision grinder, the surface roughness $R \mathrm{a}=0.2 \mu \mathrm{m}$. The friction ring-block was the $\mathrm{GCr} 15$ steel ring which was formed after the quenching and drawing temper. Its surface received ground finish and polishing. Then, it was finished on the diamond sandpaper with the granularity of $800 \#$ and $1000 \#$, and the specimen surface was ground to the mirror surface.

\subsection{Experimental Scheme}

The friction coefficient could be acquired through the mean value of the ratios of frictions to normal forces, both of which were read out from the tribometer directly. The wear status was measured based on the wear rate and calculated according to (1) and (2).

$$
V=\left\{R^{2} \arcsin \frac{b}{2 R}-\frac{b}{2}\left[L^{2}-\left(\frac{b}{2}\right)^{2}\right]^{1 / 2}\right\}
$$

where, V-Wear volume (mm3); R-Ring-specimen radius $(\mathrm{mm})$; b-Grinding-crack width $(\mathrm{mm})$; L-Grinding-crack length $(\mathrm{mm})$.

$$
W=\frac{V}{D P}
$$

where, $\mathrm{W}$-Wear rate $\left(\mathrm{mm}^{3} / \mathrm{m} \mathrm{N}\right)$; D-Sliding distance $(\mathrm{m})$; $\mathrm{P}-\operatorname{Normal} \operatorname{load}(\mathrm{N})$.

A PGI800 coarseness profiling instrument was used to test the width $b$ and the length $\mathrm{L}$ of the grinding cracks on the specimen surface. An S-3500N SEM was employed to observe and analyze the morphology of the wearing surfaces of the specimen.

\section{RESULT ANALYSIS}

\subsection{Testing of Specimen Density and Apparent Porosity}

Compared with common ceramics, the nanometric zirconia ceramics has a higher density. An electronic analytical balance was used for weighing, and the Archimedes drainage method was used to test the density and the apparent porosity of the specimens. During the measurement, three specimens (specimens A, B, and C) were selected to reduce artificial measurement errors. Each specimen was measured for six times, with the mean value being taken finally. 
The density testing results for nanometric zirconia ceramics are shown below (Fig. 1). Fig. (1) show that the density was $6.03 \mathrm{~g} / \mathrm{cm}^{3}$ and the apparent porosity was $0.32 \%$.

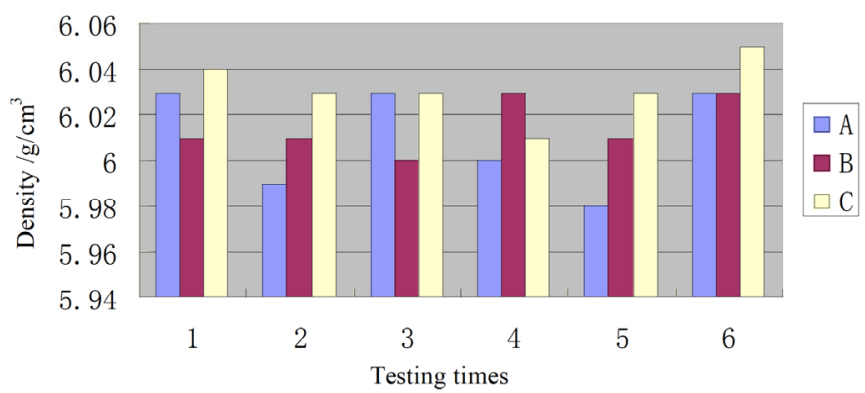

Fig. (1). Density testing results for nanometric zirconia ceramics.

\subsection{Determination of Linear Contraction}

The length variation of the nanometric zirconia ceramics specimens before and after sintering was measured with a vernier caliper. The mean linear contraction of the specimens was $21.96 \%$.

\subsection{Flexural Strength Test}

The flexural strength was an important indication for the mechanical properties of materials. Before the test, the specimens were polished, and cleaned with alcohol and dried; then, the three-point flexural strength was tested by a CMT6000 universal tester. The specimens were made into rectangular parts with the dimension of $5 \mathrm{~mm} \times 4.5 \mathrm{~mm} \times 24$ $\mathrm{mm}$, with three per group and five replicates of test. The testing conditions followed the IS06872 criteria, with diameter of the pressure head of $4 \mathrm{~mm}$, the sensor force of $10 \mathrm{~kg}$, the span of $20 \mathrm{~mm}$, and the loading speed of $0.5 \mathrm{~mm} / \mathrm{min}$. The test results of the flexural strength were shown as in Fig. (2). The mean flexural strength of nanometric zirconia ceramics was $890.33 \mathrm{Mpa}$.

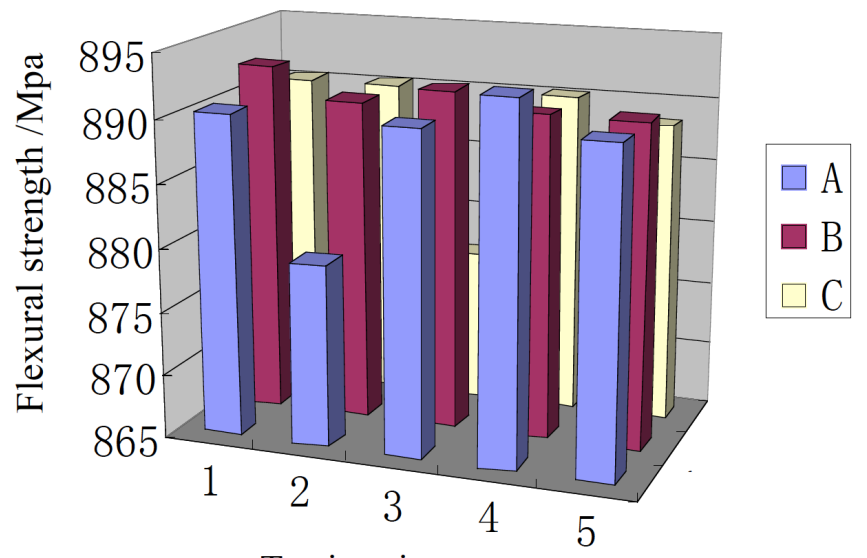

Testing times

Fig. (2). Flexural strength of nanometric zirconia ceramics.

\subsection{Fracture Toughness Test}

The fracture toughness of nanometric zirconia ceramics was measured with the single edge notched beam method. The specimens were made into parts in the dimension of $4 \times 3 \times 25 \mathrm{~mm}$ before a $0.2 \mathrm{~mm}$-wide and $2 \mathrm{~mm}$-deep notch was made on it. At the test span of $16 \mathrm{~mm}$, the sensor force of $10 \mathrm{~kg}$ and the loading speed of $0.5 \mathrm{~mm} / \mathrm{min}$, the three-point bending method was adopted to measure the fracture toughness KIC on a CMT6000 universal electronic tester. The fracture toughness of nanometric zirconia ceramics was acquired from testing and calculations, as shown in Fig. (3). The mean fracture toughness $6.02 \mathrm{Mpa} \cdot \mathrm{m}^{1 / 2}$ can be attained form the figure.

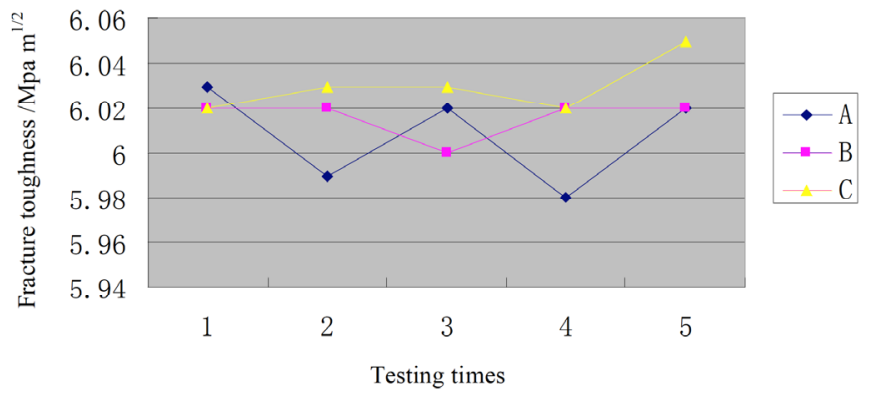

Fig. (3). Fracture toughness testing results for nanometric zirconia ceramics.

\subsection{Hardness Test}

A FUTURE-TECH Microscopic Vickers was used to measure the hardness of nanometric zirconia ceramics. First, the surface to be measured was polished, wiped with alcohol and dried for reservation; then, the Microscopic Vickers was used to measure the surface to be measured. In the measurement, each group was measured for three times at different sites on the same plane of specimen, and the mean value was obtained.

The load on the measuring head of the Microscopic Vickers was $500 \mathrm{gf}$, and the dwell time was $15 \mathrm{~s}$. The indentation shape was observed through eyepieces, and the indentation size was measured. The mean Vickers hardness of the measured specimen was HV1241.

\subsection{Mechanical Properties Comparison}

According to the comparison with several other kinds of dental prosthesis ceramics in terms of the density, flexural strength, fracture toughness and Vickers hardness, the flexural strength and the fracture toughness of nanometric zirconia ceramics had been significantly improved and met the requirements of oral medicine. The property comparison between the nanometric $\mathrm{ZrO}_{2}(\mathrm{Y}-\mathrm{TZP})$ ceramics and other kinds dental ceramics were shown as in Figs. $(\mathbf{4}, \mathbf{5})$.

\subsection{Load Effects on Friction Coefficient}

Under the lubrication of artificial saliva, the variation of the measured friction coefficient with the load and rotation speed was shown in the Fig. (6). With the gradual increase of the normal load from $100 \mathrm{~N}$ to $600 \mathrm{~N}$, the friction coefficient of nanometric $\mathrm{ZrO}_{2}$ ceramics trended to increase. Because the load upon the specimen increased, the friction generated between two contact surfaces also grew. According to the formula for calculating the friction coefficient, a conclusion could be drawn that the friction coefficient increased with the load, but the rise trended to be smoothed.

\subsection{Effect of Rotation Speed on Friction Coefficient}

It was clear from the Fig. (6) that the friction coefficient decreased with the increase of the rotation speed. The increased rotation speed caused the plastic deformation on the friction surface and consequently, caused the contact surface heated and softened, playing a role of lubrication. 
Therefore, the friction coefficient trended to decrease with the increase of rotation speed.

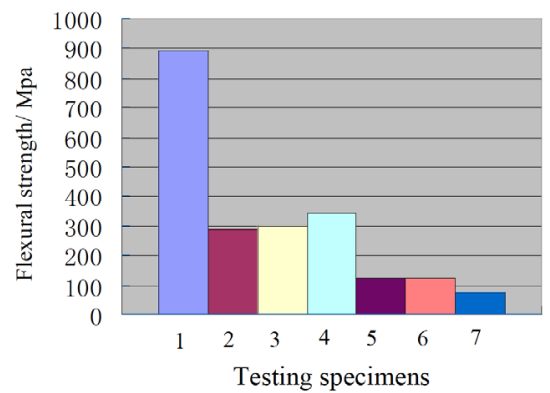

I-Nanometric $\mathrm{ZrO}_{2}$ ceramics, $2-\mathrm{ZrO}_{2}$ ceramics; $3-\mathrm{Al}_{2} \mathrm{O}_{3}(95)$

4- $\mathrm{Al}_{2} \mathrm{O}_{3}(99)$

5-Cast ceramics;

6-Hotpressed ceramics;

7-Cutting ceramics

Fig. (4). Flexural strength comparison with different dental ceramics.

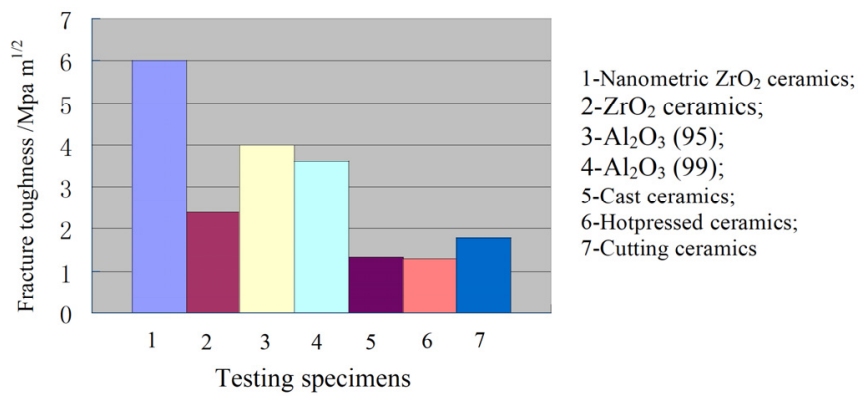

Fig. (5). Fracture toughness comparison with different dental ceramics.

\subsection{Wear Rate}

A PGI800 coarseness profiling instrument was used to test the width $\mathrm{b}$ and the length $\mathrm{L}$ of grinding cracks, as shown as in Fig. (7).

The relationships of the wear rate of nanometric $\mathrm{ZrO}_{2}$ ceramics with the load and the rotation speed under the lubrication of artificial saliva were shown as in Fig. (8). The Fig. (8) indicated that the wear rate of nanometric $\mathrm{ZrO}_{2}$ ceramics trended to increase with the increase of load when the rotation speed was fixed. When the load was fixed, the wear rate of nanometric $\mathrm{ZrO}_{2}$ ceramics trended to decrease with the increased rotation speed. When the load was lower

than $500 \mathrm{~N}$, the wear rate of nanometric $\mathrm{ZrO}_{2}$ ceramics varied within the range of $10^{-7}-10^{-6} \mathrm{~mm}^{3} / \mathrm{N} . \mathrm{m}$; when the load was higher than $1000 \mathrm{~N}$, the wear rate of nanometric $\mathrm{ZrO}_{2}$ ceramics was within the range of $10^{-6}-10^{-5} \mathrm{~mm}^{3} / \mathrm{N} . \mathrm{m}$, and the wear was intensified. The wear rate was higher at lower speed and lower at higher speed. With the increase of the rotation speed, the embossment between contact surfaces ground each other quickly, and the contact surfaces of the friction pair became rather smoothed in a short time. The generation of oxidation film was accelerated, and the further wear of the friction pair was alleviated, which caused the wear rate decrease. Besides, the increase of the rotation speed caused the temperature at the contact surfaces of the friction pair increase. The transfer of surface-layer elements and adhesive wear might occur between the two contact surfaces due to the friction heat. The surface-layer elements filled the wear surface, so the wear rate was low. During the frictional wear, the abrasive dust generated under large load at a high rotation speed might very easily be bonded to form a surface layer which somewhat protected the friction pair. Thus, the wear was reduced, and the wear rate decreased.

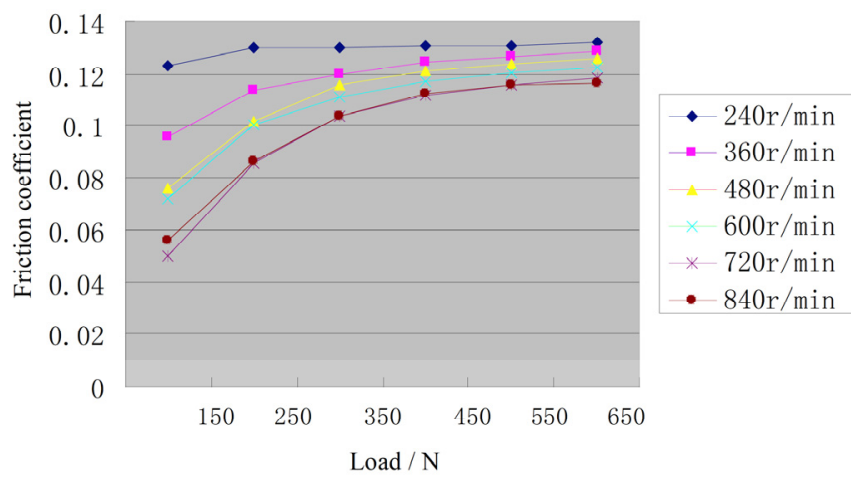

Fig. (6). Effects of nanometric $\mathrm{ZrO}_{2}$ ceramics load and rotationspeed variation on friction coefficient.

\subsection{Wear Surface Morphology}

In order to analyze the wear mechanism of nanometric zirconia ceramics, an S-3500 SEM was used to observe the surface morphology after the wear. The Fig. (9a) showed the

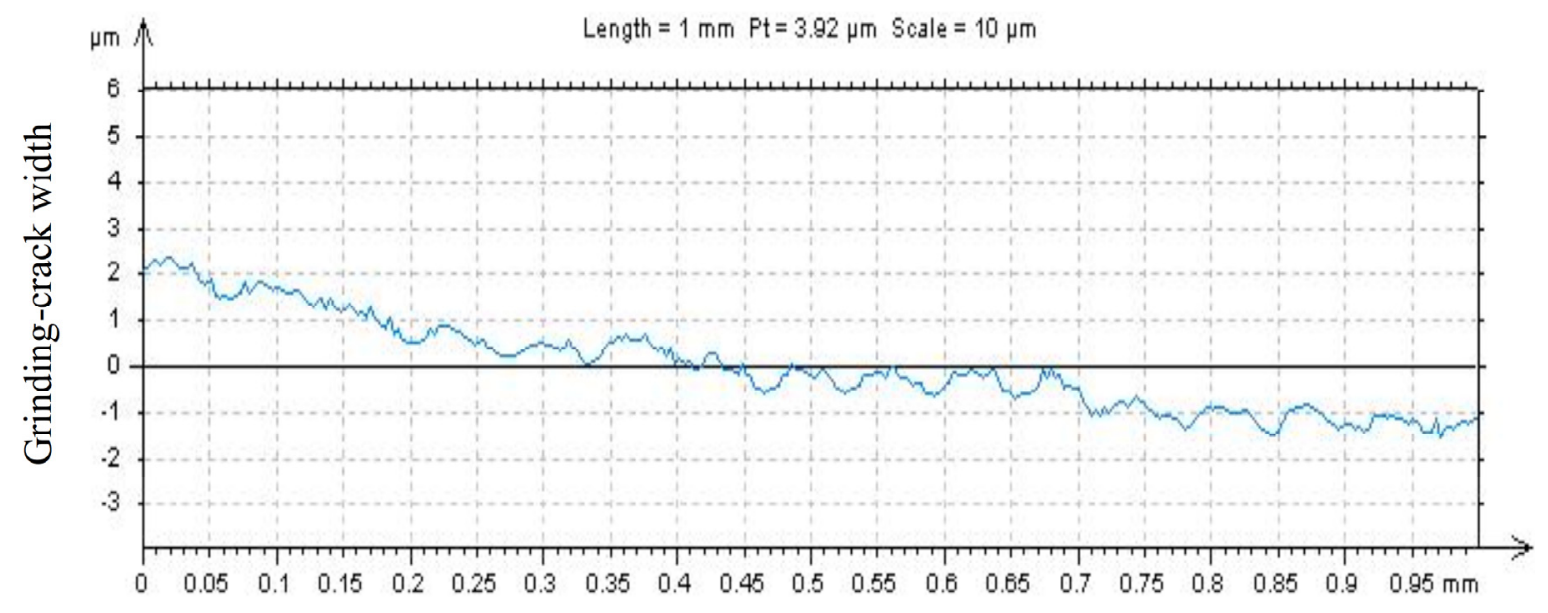

Grinding-crack length (load of $100 \mathrm{~N}$ and rotation speed of $360 \mathrm{r} / \mathrm{min}$ )

Fig. (7). Effects on width and length variation of grinding cracks $v s$ load and rotation speed. 
surface morphology of nanometric zirconia ceramics with the wear being conducted under the load of $500 \mathrm{~N}$ at the rotation speed of $600 \mathrm{r} / \mathrm{min}$. It was noticed that the wear surface of nanometric $\mathrm{ZrO}_{2}$ ceramics became smoother, with only scanty amount of fuzzy furrow traces. In this wear course, wear occurred in the form of microscopic plowing, which had a polishing effect. The wear mechanism in this period was the abrasive wear and microscopic plowing.

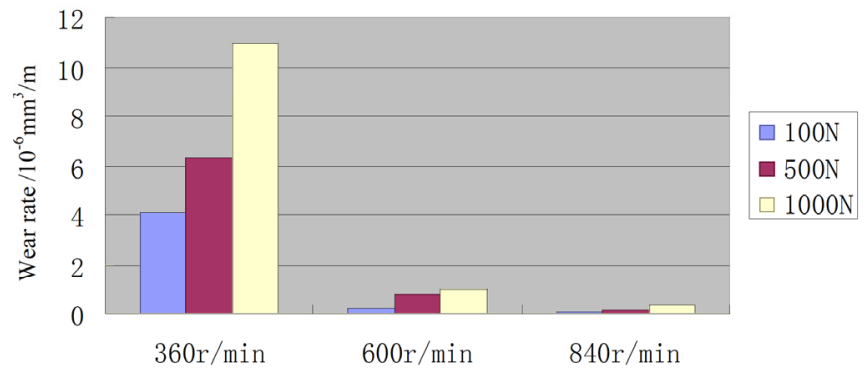

Fig. (8). Wear rate variation of nanometric $\mathrm{ZrO}_{2}$ ceramics $v s$ load and rotation speed.

The Fig. (9b) showed the SEM images about the wear surface morphology of nanometric $\mathrm{ZrO}_{2}$ ceramics. Compared with Fig. (9a), certain coarseness was noticed at the wear surface of nanometric $\mathrm{ZrO}_{2}$ ceramics. There were significant plastic furrow traces, and uneven surfaces emerged. Significant plastic deformation appeared. The wear was intensified, and the wear rate grew. The wear mechanism was the plastic deformation and microscopic plowing.

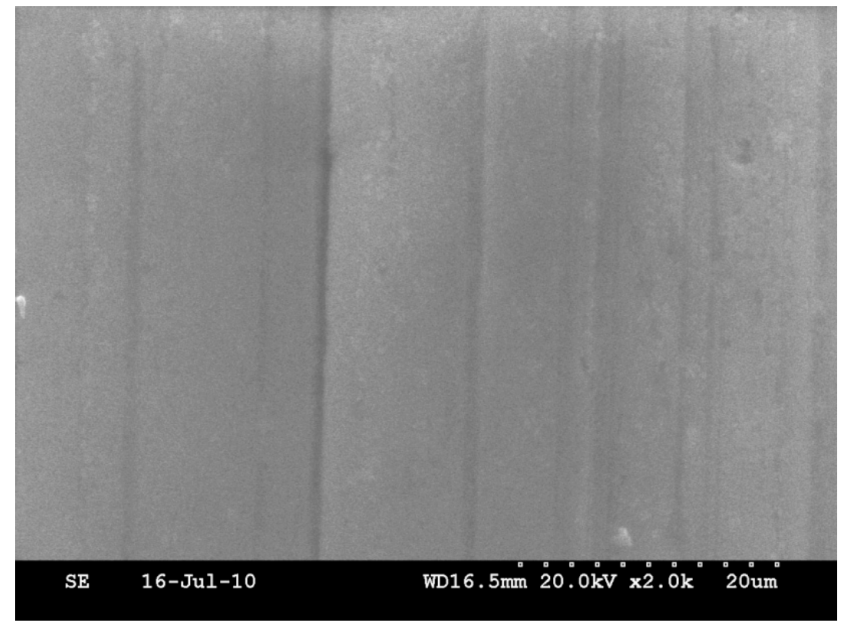

(a)

Fig. (9). SEM morphology of 3Y-TZP wear surface.

\section{CONCLUSION}

1. The flexural strength of the test specimens $\geq 890 \mathrm{MPa}$, the fracture toughness $\geq 6 \mathrm{Mpa} . \mathrm{m}^{1 / 2}$, the Vickers hardness $\geq 1240 \mathrm{MPa}$, the linear contraction $\geq 21 \%$, and the apparent porosity $\geq 0.32 \%$. Fully satisfying the requirements in oral medicine, the ceramic is an ideal material for biological joints and dental prosthesis.
2. The friction coefficient of nanometric $\mathrm{ZrO}_{2}$ ceramics increased with the load. Under the same load, the friction coefficient under high-speed rotation was lower than that under low-speed rotation.

3. The friction coefficient under lubrication was between 0.05 and 0.14 . Under identical loading and friction conditions, the friction coefficient of nanometric $\mathrm{ZrO}_{2}$ ceramics was lower than that of $\mathrm{ZrO}_{2}$ ceramics.

4. The wear rate of nanometric $\mathrm{ZrO}_{2}$ ceramics was proportional to the load and in inverse proportion to the revolution. Compared with $\mathrm{ZrO}_{2}$ ceramics, nanometric $\mathrm{ZrO}_{2}$ ceramics had a lower wear rate, and its wear resistance was better than that of $\mathrm{ZrO}_{2}$ ceramics.

5. The wear mechanism of nanometric $\mathrm{ZrO}_{2}$ ceramics was micromachining and plastic deformation while the wear mechanism of $\mathrm{ZrO}_{2}$ ceramics was brittle fracture and abrasive wear.

\section{ACKNOWLEDGEMENT}

This research was financially supported by the National Natural Science Foundation of China (50875138); the Shandong Provincial Natural Science Foundation of China (Z2008F11, ZR2009FZ007) and the Specialized Construct Fund for Taishan Scholars.

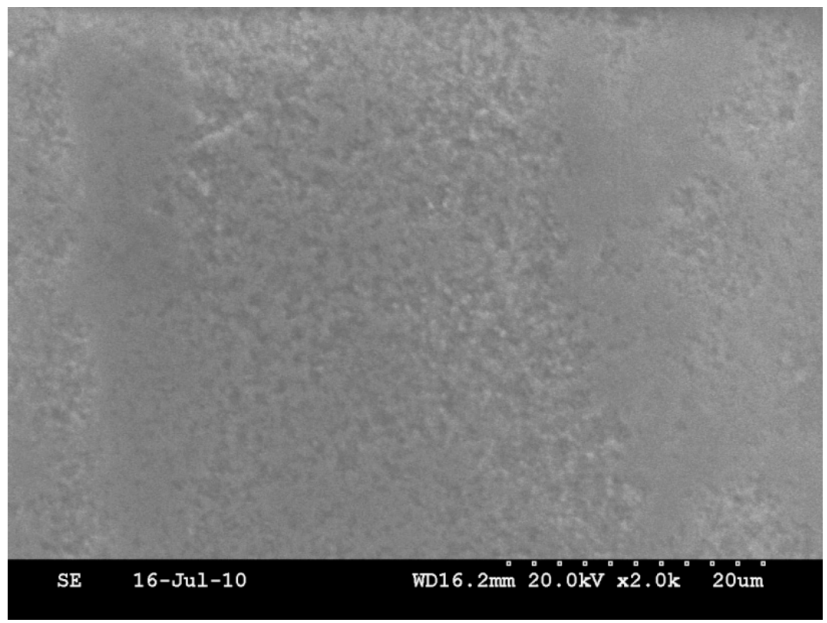

(b)

\section{REFERENCES}

[1] Atai M, Yassini E, Amini M, et al. The effect of aleucitecontaining ceramic filler on the abrasive wear of dental composites. Dent Mater 2007; 23: 1181-7.

[2] Bandlish RB, McDonald AV, Setchell DJ. Assessment of the amount of remaining coronal dentinein root-treated teeth. J Dent 2006; 34: 699-708.

[3] Deng Y, Lawn BR, Lloyd IK. Characterization of damage modes indental ceramic bilayer structures. J Biomed Mater Res 2003; 63: 137-45. 
[4] Li CH, Cai GQ, Xiu SC. Hydrodynamic Pressure Modeling and Verification of Contact Zone on Abrasive Jet Finishing with Grinding Wheel as Restraint. Acta Armamentarii 2007; 28: 202-5.

[5] Li C, Hou Y, Ding Y, Cai G. Feasibility investigations on compound process: a novel fabrication method for finishing with grinding wheel as restraint. Int J Comput Mater Sci Surf Eng 2011; 4: $55-68$.

[6] Li Changhe, Hou Yali, Liu Zhanrui, Ding Yucheng. Investigation into temperature field of nano-zirconia ceramics precision grinding. Int J Abrasive Technol 2011; 4: 52 - 65.

[7] Sein H, Ahmed W, Jackson $\mathrm{M}$, et al. Performanceand characterization of CVD diamond coated, sintered Diamond and
WC-Cocutting tools for dentaland micromachining applications. Thin Solid Films 2004; 447-448: 455-61.

[8] Tomba AG, Cavalieri AL. Surface finish and mechanical strength of dense alumina. Mater Res Bull 2000; 35: 1077-85.

[9] Wua M, Tinschert J, Augthun M, et al. Application of laser measuring, numerical simulation and rapid prototyping to titanium dental castings. Dent Mater 2001; 17: 102-8.

[10] Yin L, Song XF, Song YL, et al. An overview of invitro abrasive finishing \& CAD/CAM of bioceramics in restorative dentistry. Int $\mathbf{J}$ Machine Tools Manufacture 2006; 46: 1013-26.

(C) Li et al.; Licensee Bentham Open.

This is an open access article licensed under the terms of the Creative Commons Attribution Non-Commercial License (http://creativecommons.org/licenses/by-nc/3.0/) which permits unrestricted, non-commercial use, distribution and reproduction in any medium, provided the work is properly cited. 